\title{
Socio-demographic characteristics and nutritional status of individuals by stages of change for dietary fat reduction.
}

\begin{abstract}
Changes in lifestyle and food habits have been implicated in the increasing rate of nutrition related chronic diseases in Malaysia. A cross-sectional study was conducted to identify sociodemographic characteristic and nutritional status of individuals by their readiness to reduce dietary fat intake. A total of 202 non-academic staff aged 18-56 years at Universiti Putra Malaysia participated in the study. Information on demographic, socio-economic and stages of change related to dietary fat reduction were collected using a pre-tested interviewadministered questionnaire. Subjects were measured for weight, height and waist circumference. Fasting blood through venipuncture was obtained for triglycerides, LDL-, HDL- and total cholesterol. Energy and dietary fat intake were estimated based on two days $24 \mathrm{~h}$ diet recall. Chi-square test and Analysis of Covariance (ANCOVA) were used for data analysis. Of the respondents, about $12 \%$ reported reduced fat intake, $20 \%$ were not committed to change and more than half $(68 \%)$ were in preparation stage. There was no significant association between stages of change and socio-demographic factors. Body mass index was highest in preparation group (Mean $\pm S E=24.93 \pm 0.35 \mathrm{~kg} / \mathrm{m} 2$ ) $[\mathrm{F}=5.686 ; \mathrm{p}<0.01]$. Men in action/maintenance group (Mean $\pm \mathrm{SE}=76.22 \pm 4.17 \mathrm{~cm}$ ) had significantly lower adjusted mean waist circumference than those in preparation group (Mean $\pm \mathrm{SE}=89.77 \pm 1.85$ $\mathrm{cm})[\mathrm{F}=5.324, \mathrm{p}<0.01]$. No significant difference across stages was observed in waist circumference for women, lipid profile, caloric and fat intake. It is important to identify characteristics of individuals by their readiness to change dietary behaviors so that effective nutrition strategies can be developed and implemented to meet their dietary needs and goals.
\end{abstract}

Keyword: Behavioral change; Fat reduction; Food habits 